\title{
Multimodal management of arteriovenous malformations of the basal ganglia and thalamus: factors affecting obliteration and outcome
}

\author{
Venkatesh S. Madhugiri, MCh, ${ }^{1,3}$ Mario K. C. Teo, FRCS, ${ }^{1,3}$ Erick M. Westbroek, MD, ${ }^{1,3}$ \\ Steven D. Chang, MD,, 3 Michael P. Marks, MD, ${ }^{1-3}$ Huy M. Do, MD, ${ }^{1-3}$ Richard P. Levy, MD, PhD, ${ }^{4}$ and \\ Gary K. Steinberg, MD, PhD, 1,3
}

Departments of ${ }^{1}$ Neurosurgery and ${ }^{2}$ Radiology, and ${ }^{3}$ Stanford Stroke Center, Stanford University School of Medicine, Stanford; and ${ }^{4}$ Department of Radiation Oncology, Loma Linda University, Loma Linda, California

\begin{abstract}
OBJECTIVE Arteriovenous malformations (AVMs) of the basal ganglia and thalamus are particularly difficult lesions to treat, accounting for $3 \%-13 \%$ of all AVMs in surgical series and $23 \%-44 \%$ of malformations in radiosurgery series. The goal of this study was to report the results of multimodal management of basal ganglia and thalamic AVMs and investigate the factors that influence radiographic cure and good clinical outcomes.

METHODS This study was a retrospective analysis of a prospectively maintained database of all patients treated at the authors' institution. Clinical, radiological, follow-up, and outcome data were analyzed. Univariate and multivariate analyses were conducted to explore the influence of various factors on outcome.

RESULTS The results and data analysis pertaining to 123 patients treated over 32 years are presented. In this cohort, radiographic cure was achieved in $50.9 \%$ of the patients. Seventy-five percent of patients had good clinical outcomes (stable or improved performance scores), whereas $25 \%$ worsened after treatment. Inclusion of surgery and radiosurgery independently predicted obliteration, whereas nidus diameter and volume predicted clinical outcomes. Nidus volume/ diameter and inclusion of surgery predicted the optimal outcome, i.e., good clinical outcomes with lesion obliteration.
\end{abstract}

CONCLUSIONS Good outcomes are possible with multimodal treatment in these complex patients. Increasing size and, by extension, higher Spetzler-Martin grade are associated with worse outcomes. Inclusion of multiple modalities of treatment as indicated could improve the chances of radiographic cure and good outcomes.

https://thejns.org/doi/abs/10.3171/2018.2.JNS172511

KEYWORDS arteriovenous malformation; basal ganglia; multimodal treatment; radiosurgery; thalamus; microsurgery; vascular disorders

A RTERIOVENOUS malformations (AVMs) of the basal ganglia and thalamus (BGT) account for $3 \%-13 \%$ of all AVMs in surgical series $7,8,12,16$ and $23 \%-44 \%$ of malformations in radiosurgery series. ${ }^{10,13,18,25,26,30}$ These lesions have a worse natural history and higher annual hemorrhage rates than superficial AVMs. ${ }^{12,22,25,26}$ The treatment outcomes of deep-seated AVMs remain far from satisfactory at present. Most publications reporting uniformly good clinical and radiological outcomes include only small AVMs (the majority of them $<3 \mathrm{~cm}$ ) ${ }^{1,14,23,26,28}$ Recent and more comprehensive series reporting the results of stereotactic radiosurgery (SRS) for AVMs have emphasized that for large deep-seated AVMs, the outcomes remain poor. ${ }^{22}$

Several modalities of treatment have been used for
AVMs. For BGT AVMs, the first line of therapy considered is generally SRS. However, obliteration rates after SRS are reported to be lower for BGT AVMs than for superficial pial AVMs. While endovascular treatment (EVT) of these AVMs can be performed with low risk, EVT is rarely curative and is generally used as an adjunct to SRS or microsurgery. ${ }^{24,33}$ Thus, there remains a definite role for open surgery in the management of BGT AVMs. Many authors have reported good results after microsurgical resection of carefully selected lesions, as both a standalone treatment and, as is more common, part of a multipronged attack on these lesions. ${ }^{8,16,17,21,31,32}$ Multimodal management of AVMs has evolved primarily because no single therapy has been able to effectively obliterate complex AVMs

ABBREVIATIONS AVM = arteriovenous malformation; BGT = basal ganglia and thalamus; $E V T=$ endovascular treatment; GKS = Gamma Knife surgery; LINAC = linear accelerator; $\mathrm{mRS}$ = modified Rankin Scale; PreTP = pretreatment period; PostTP = posttreatment period; SRS = stereotactic radiosurgery.

SUBMITTED October 9, 2017. ACCEPTED February 23, 2018.

INCLUDE WHEN CITING Published online August 17, 2018; DOI: 10.3171/2018.2.JNS172511. 
with acceptable morbidity rates. Importantly, outcomes are improved when several disciplines pool their expertise to tackle these lesions. ${ }^{4}$ We have been proponents of a comprehensive multidisciplinary approach for the management of AVMs for over 3 decades and have found that this strategy substantially improves patient outcomes.

The 2 markers of successful AVM treatment are radiographic obliteration of the lesion and maintenance of (or improvement in) pretreatment neurological status. In this paper, we describe our experience with multimodal treatment of BGT AVMs spanning over 3 decades. We also identify the factors that are associated with radiographic cure, good clinical outcomes, and optimal outcomes, which would be a combination of good clinical outcome with radiologic cure.

\section{Methods \\ Patients}

The prospectively maintained Stanford AVM database (MD Analyze, Medtamic Inc.) was queried to identify all consecutive patients with BGT AVMs referred to our center between 1984 and 2016 (32 years). All patient-, lesion-, and outcome-related data were analyzed.

\section{Hemorrhage}

Hemorrhage rates were calculated over 2 periods of time: the pretreatment period (PreTP) and the posttreatment period (PostTP). The period from birth to the institution of the first session of therapy reflects the natural history of these lesions, assuming them to be congenital AVMs, and was defined as the PreTP. The period between treatment and radiographic obliteration of the lesion was the PostTP. It is not well known if these treatments reduce the risk of hemorrhage in the interim. Therefore, the number of hemorrhages during the PreTP and PostTP was computed using the person-year method. ${ }^{29}$

\section{Treatment Modalities}

Treatment plans were determined by the multidisciplinary neurovascular team. In cases in which SRS was administered, various delivery systems, radiation modalities, and doses were employed at different time points during this study period. These include heavy particle Bragg peak irradiation, proton-beam radiation therapy, linear accelerator (LINAC)-based radiosurgery, Gamma Knife surgery (GKS; Elekta Instruments AB), and CyberKnife radiosurgery (Accuray Inc.). Similarly, EVT was performed using a number of embolic agents, including polyvinyl alcohol, histacryl, $N$-butyl-2-cyanoacrylate, and Onyx (Medtronic). Provocative testing with amytal was done for almost all patients during EVT, once superselective catheterization of the feeding artery was performed. Embolization was aborted if any changes in neurophysiological parameters were noted at this time. No more than $50 \%$ of the AVM was embolized in any single stage.

Surgery was performed in the following select cases: if there was a large hematoma that required evacuation, if the AVM had not been obliterated 3 years after SRS, if EVT was not feasible, or if multiple other treatment sessions had failed to obliterate the lesion. Partial or staged resection was performed if complete excision in a single stage was considered to be too risky. Various adjuncts, including controlled hypotension, mild hypothermia, burst suppression, neuronavigation, intraoperative electrophysiological monitoring, functional testing, microvascular Doppler probes, indocyanine green angiography, and intraoperative angiography, were employed as necessary. Different microsurgical approaches were used depending on the eloquence of the AVM location, proximity to an ependymal or pial surface, and the presence of hematoma. Surgical approaches included anterior and posterior interhemispheric transcallosal, frontotemporal transsylvian, occipital transtentorial, supracerebellar infratentorial, and transsulcal through the frontal, temporal, or parietal sulcus. Patients were managed in the ICU after surgery or EVT, with the mean arterial pressure tightly controlled at $60-70 \mathrm{~mm} \mathrm{Hg}$ for the first 24 hours. All patients underwent head CT scanning on the first postprocedure day and if no hematoma or edema was noted, the mean arterial pressure was gradually allowed to rise to the patient's baseline level over the next few days.

All patients underwent MRI 6 months after treatment and annually thereafter, with confirmatory angiography performed at 3-4 years or if the MRI study suggested obliteration.

\section{Outcomes}

If a follow-up visit had occurred within 6 months of the time of collecting data, information from this visit was used. For other patients, telephonic follow-up was obtained. Outcomes were measured using the modified Rankin Scale (mRS). ${ }^{2,27}$ Neurological status was classified as good (mRS scores $0-2$ ) or poor (mRS scores 3-6). Clinical outcomes were dichotomized as good if the patients had either improved by at least $1 \mathrm{mRS}$ score or remained status quo, or poor if they had worsened at last follow-up. Analysis of radiographic obliteration for the SRS group included only those patients who had at least 3 years of follow-up after the initial treatment. Radiological obliteration was defined as total disappearance of the nidus and all early draining veins on digital subtraction angiography. An optimal outcome was defined as angiographic cure in a patient with a good clinical outcome.

\section{Statistical Methods}

Statistical analyses were carried out using the Stata (version 14.2, StataCorp LLC) software package. The alpha level was set at 0.05 for significance.

\section{Results}

\section{Patients and Lesions}

Over the study period, 123 patients with BGT AVMs were treated at Stanford University; 7 of these patients had undergone their first session of treatment (EVT or SRS) elsewhere. Only basic demographic and lesion-related data were available for 1 patient who was an adult with a Spetzler-Martin grade V BGT AVM; this patient was therefore excluded from all subsequent statistical analyses. All but 3 of the patients were referred to us with symptoms/signs referable to the AVM. All patients opted to be 
TABLE 1. Patient and lesion characteristics

\begin{tabular}{|c|c|c|c|c|}
\hline \multirow[b]{2}{*}{ Parameter } & \multicolumn{3}{|c|}{$\mathrm{SMG}^{*}$} & \multirow{2}{*}{$\begin{array}{l}\text { Difference Btwn Lower- } \\
\text { \& High-Grade Lesions }\end{array}$} \\
\hline & Overall II-V (n= 123) & $<\operatorname{IV}(\mathrm{n}=62)$ & IV or $V(n=61)$ & \\
\hline Sex & & & & $p=0.011$ \\
\hline Male & $57(46)$ & $22(35)$ & $35(57)$ & \\
\hline Female & $66(54)$ & $40(65)$ & $26(43)$ & \\
\hline Mean age at diagnosis, yrs & $24.6 \pm 14.3$ & $27.8 \pm 15.9$ & $21.2 \pm 11.7$ & $t=2.6, p=0.011$ \\
\hline \multicolumn{5}{|l|}{ Presenting symptom } \\
\hline Asymptomatic & $2(1)$ & $1(1)$ & $1(1)$ & \\
\hline Motor deficits & $67(55)$ & $28(48)$ & $39(64)$ & \\
\hline Sensory deficits/symptoms & $18(15)$ & $9(15)$ & $9(15)$ & \\
\hline Movement disorder & $5(4)$ & $1(2)$ & $4(7)$ & \\
\hline Visual complaints & $14(11)$ & $6(10)$ & $8(13)$ & \\
\hline Speech issues & $18(15)$ & $9(16)$ & $9(15)$ & \\
\hline Cognitive issues & $13(11)$ & $7(12)$ & $6(10)$ & \\
\hline Seizures & $9(7)$ & $2(3)$ & $7(11)$ & \\
\hline Hemorrhage $(n=122)$ & $87(71)$ & $47(76)$ & $40(66)$ & \\
\hline \multicolumn{5}{|l|}{$\operatorname{SMG}(n=123)$} \\
\hline II & $4(3)$ & $4(6)$ & $0(0)$ & \\
\hline III & $58(47)$ & $58(93)$ & $0(0)$ & \\
\hline IV & $48(39)$ & $0(0)$ & $48(79)$ & \\
\hline V & $13(11)$ & $0(0)$ & $13(21)$ & \\
\hline Location $(n=123)$ & & & & $\chi^{2}=21.7, p=0.002$ \\
\hline Basal ganglia & $59(48)$ & $28(45)$ & $31(51)$ & \\
\hline Thalamus & $54(44)$ & $34(55)$ & $20(33)$ & \\
\hline Both & $10(8)$ & $0(0)$ & $10(16)$ & \\
\hline \multicolumn{5}{|l|}{ Side $(n=123)$} \\
\hline $\mathrm{Lt}$ & $68(55)$ & $34(55)$ & $34(55)$ & \\
\hline Rt & $54(44)$ & $28(45)$ & $26(43)$ & \\
\hline Bilateral & $1(1)$ & & $1(2)$ & \\
\hline Mean nidus diameter, $\mathrm{cm}$ & $3.4 \pm 1.6$ & $2.2 \pm 0.7$ & $4.7 \pm 1.2$ & \\
\hline
\end{tabular}

treated rather than adapt a wait-and-watch policy; thus, there are no patients who were managed conservatively in this series. Patient and lesion characteristics are displayed in Table 1. Fifty-two patients (42\%) were in the pediatric age group $(<18$ years). The mean volume of the lesions was $51.2 \pm 47.8 \mathrm{~cm}^{3}$ (range $1.8-210 \mathrm{~cm}^{3}$, median volume $36 \mathrm{~cm}^{3}$ ). The median Spetzler-Martin grade of the lesions was III; approximately half of the lesions were high grade (Spetzler-Martin grade IV or V, $\mathrm{n}=61$ ) and the other half were lower grade (grades II-III; $\mathrm{n}=62,50 \%$ ). Most lesions $(n=108,88 \%)$ had deep venous drainage.

\section{Clinical Presentation and Hemorrhage}

The various presenting symptoms are displayed in Table 1. Raised intracranial pressure (headache, nausea, and vomiting; $n=40,32.8 \%)$ and weakness $(n=67,55 \%)$ were the most common presenting symptoms. Nine patients (7\%) presented with seizures; the mean nidus diameter in these patients was larger $(4.5 \pm 2.1 \mathrm{~cm})$ than in those patients who did not present with seizures $(3.4 \pm 1.6 \mathrm{~cm}$; $\mathrm{t}=$
$2.067, \mathrm{p}=0.041)$. Eighty-four patients $(69 \%)$ were in good neurological status (mRS scores 0-2) at presentation; however, only 2 of these patients (2\%) had absolutely no deficits (mRS score 0). During the PreTP, 1 patient with an mRS score of 1 at diagnosis deteriorated to $\mathrm{mRS}$ score 4 due to a hemorrhage, whereas 6 patients improved by at least 1 mRS point between diagnosis and treatment (Table 2).

Eighty-seven patients $(71 \%)$ presented with hemorrhage. There was no significant difference in the size of AVMs that presented with hemorrhage $(3.4 \pm 1.6 \mathrm{~cm})$ and those that did not $(3.8 \pm 1.8 \mathrm{~cm} ; \mathrm{t}=121, \mathrm{p}=0.289)$. Lesions located in the thalamus were more likely to present with hemorrhage than those located in the basal ganglia (OR $2.76,95 \%$ CI $1.09-6.99 ; p=0.004)$. None of the other factors analyzed differed between the lesions that presented with hemorrhage and those that did not. Patients had experienced 157 hemorrhages over 2878 person-years prior to diagnosis, yielding an annual PreTP hemorrhage rate of 5.5\% per person-year. In PostTP (see above), 34 repeat hemorrhages occurred over a follow-up period of 593.75 
TABLE 2. Clinical presentation and patient outcome based on mRS score

\begin{tabular}{crrrr}
\hline \multirow{2}{*}{$\begin{array}{c}\text { mRS Score Prior } \\
\text { to 1st Treatment }\end{array}$} & \multicolumn{3}{c}{ Status at Last Follow-Up* } & \\
\cline { 2 - 4 } & Worsened & Same & Improved & Total $^{*}$ \\
\hline 0 & 0 & 1 & 1 & 2 \\
\hline 1 & 6 & 16 & 2 & 24 \\
\hline 2 & 14 & 28 & 16 & 58 \\
\hline 3 & 7 & 8 & 11 & 26 \\
\hline 4 & 2 & 1 & 3 & 6 \\
\hline Total & 29 & 54 & 33 & 116 \\
\hline
\end{tabular}

* Values are presented as the number of patients.

patient-years. Thus, including all treated patients, the posttreatment annual rehemorrhage rate (before complete AVM obliteration) was $5.7 \%$ per patient-year.

\section{Treatment}

Two-thirds of the patients $(n=82,67 \%)$ had either $1(n=$ $41)$ or $2(n=41)$ treatment sessions; the other 40 patients had multiple treatments (range 3-11; Fig. 1). The median number of treatments for this cohort was 2. Sixty-eight patients $(56 \%)$ had SRS as the first treatment modality, $45(37 \%)$ had EVT, and $10(8 \%)$ had surgery as the first therapy.

In this cohort, $109(89 \%)$ patients had one or more sessions of SRS. Of the 109 patients, $70(64.2 \%)$ had a single session of SRS and the others had between 2 and 8 sessions. Overall, 146 sessions of SRS were administered, a mean of 1.3 sessions per patient. Types of SRS performed were helium ion radiation therapy $(n=64)$, CyberKnife $(n$ $=34)$, proton-beam radiation therapy $(\mathrm{n}=24)$, LINAC $(\mathrm{n}=$ 13), GKS $(n=3)$, and not known $(n=8)$. Fractionated SRS was performed in 10 patients, while 2 patients underwent volume-staged SRS. Doses ranged from 11 to $35 \mathrm{~Gy}$ with a mean dose to the periphery of 20.9 Gy. The overall angiographic obliteration rate for patients who had received SRS as part of their treatment plan was $42 \%$ (34.7\% for high grade, $56.8 \%$ for lower grade). Post-SRS hemorrhage occurred in 20 patients (18.3\%), 6 patients (5.5\%) had radiation necrosis, and 13 patients developed fresh post-SRS deficits (11.9\%), possibly due to edema (hemiparesis in 12 , seizures in 1). Patients who had post-SRS hemorrhage had larger lesions $(4.3 \pm 1.1 \mathrm{~cm})$ than those who did experience hemorrhage after SRS $(3.5 \pm 1.8 \mathrm{~cm} ; \mathrm{t}=2.78, \mathrm{p}=0.008)$ and, by extension, patients with high-grade lesions were more likely to bleed than those with intermediate Spetzler-Martin grade III lesions $\left(\chi^{2}=8.38, p=0.004\right)$. The rate of developing permanent deficits after SRS was 9.7 per 100 sessions. Forty-two patients had only SRS as the treatment for the AVM; angiographic follow-up data were available for 35 of these patients. Radiographic cure was documented in $43 \%(n=15)$ of patients who had at least 3 years of follow-up after SRS. The obliteration rate was $57.7 \%$ for Spetzler-Martin grade II-III AVMs and $0 \%$ for higher-grade lesions $\left(\chi^{2}=10.7, \mathrm{p}<0.001\right)$.

Overall, 66 patients (54\%) had a total of 141 sessions of EVT. The median number of EVT sessions was 3 (range 1-11) (Table 3). In 3 sessions no embolizable vessels were found, in 2 sessions the microcatheter could not be navigated into the feeding artery, and in 1 session the proce- dure was abandoned due to changes in the somatosensory evoked potentials after amytal injection. Twenty-two patients (of the 66 who underwent EVT) had complications after EVT (33\%); half of these complications $(n=11,17 \%)$ persisted as permanent neurological deficits. Two patients each had dissection of the internal carotid artery and gluing of the catheter in the vessel, and 7 patients had fresh or worsened visual deficits. Five patients ultimately experienced hemiparesis. The incidence of permanent neurological deficits after embolization was 7.8 per 100 procedures.

Thirty-six patients (29\%) had a total of 53 surgical procedures (mean 1.5 procedures/patient). Twenty-four patients $(75 \%)$ had only 1 procedure and the remaining patients had between 2 and 4 procedures. Ten patients had postsurgical complications (28\%). Complications were hematoma $(\mathrm{n}=2)$, hydrocephalus $(\mathrm{n}=1)$, hemiparesis $(\mathrm{n}=$ $5)$, aphasia $(n=1)$, midbrain syndrome $(n=1)$, and subdural hematoma $(n=1)$. In 4 patients, permanent neurological deficits developed after surgery, while in the other 6 , the deficits had resolved before last follow-up. The rate of permanent deficits after surgery was therefore 7.5 per 100 procedures. Five patients had surgery as their only treatment. These lesions were all $<3 \mathrm{~cm}$ in size, low grade (Spetzler-Martin grades I-III), and had presented with hemorrhage (Fig. 2). Four of the 5 had radiographic cure (80\%), and the fifth patient was lost to follow-up.

\section{Radiographic Cure}

Posttreatment radiographic follow-up data were available for 106 patients (86\%); overall, 54 patients $(51 \%)$ had radiographic cure on angiography (Table 3). More lowergrade (Spetzler-Martin grades II-III) lesions (63\%) were obliterated than high-grade lesions (39\%; OR 2.7, 95\% CI 1.26-5.87; $\mathrm{p}=0.013)$. Lesions that were obliterated were smaller in diameter $(3.0 \pm 1.6 \mathrm{~cm})$ than those that were not $(3.9 \pm 1.6 \mathrm{~cm}, \mathrm{p}=0.01)$; similarly, the volume of those lesions that were obliterated was smaller $\left(26.5 \pm 29 \mathrm{~cm}^{3}\right)$ than that of persistent AVMs $\left(62.4 \pm 45.7 \mathrm{~cm}^{3}, \mathrm{p}=0.009\right)$. Inclusion of SRS in the treatment protocol was associated with higher rates of obliteration $(n=42,77.8 \%)$ than when SRS was not administered (22.2\%; OR 13.17, 95\% CI 2.1-295.3; $\mathrm{p}=0.002$ ). Similarly, inclusion of surgery (OR 5.4, 95\% CI $2.2-14.4 ; \mathrm{p}<0.001)$ in the treatment protocol improved the odds of achieving radiographic cure. No other factors were associated with nidus obliteration. Multivariate analysis showed the inclusion of surgery $\left(\mathrm{R}^{2}=0.5, \mathrm{p}<0.001\right)$ and inclusion of SRS $\left(\mathrm{R}^{2}=0.1, \mathrm{p}=0.002\right)$ to be the only independent predictors of angiographic obliteration. We generated Kaplan-Meier plots to display the probability of nidus obliteration over time; the Cox proportional hazards regression showed that only the inclusion of surgery significantly improved the probability of obliteration (Fig. 3).

We then performed separate multivariate analyses for lower- and high-grade lesions. For Spetzler-Martin grade II-III lesions, none of the analyzed variables predicted nidus obliteration after treatment. For high-grade lesions, inclusion of surgery in the treatment paradigm independently predicted obliteration $(\mathrm{z}=3.07, \mathrm{p}=0.002)$.

\section{Follow-Up and Clinical Outcomes}

Follow-up clinical data were available for 116 of the 

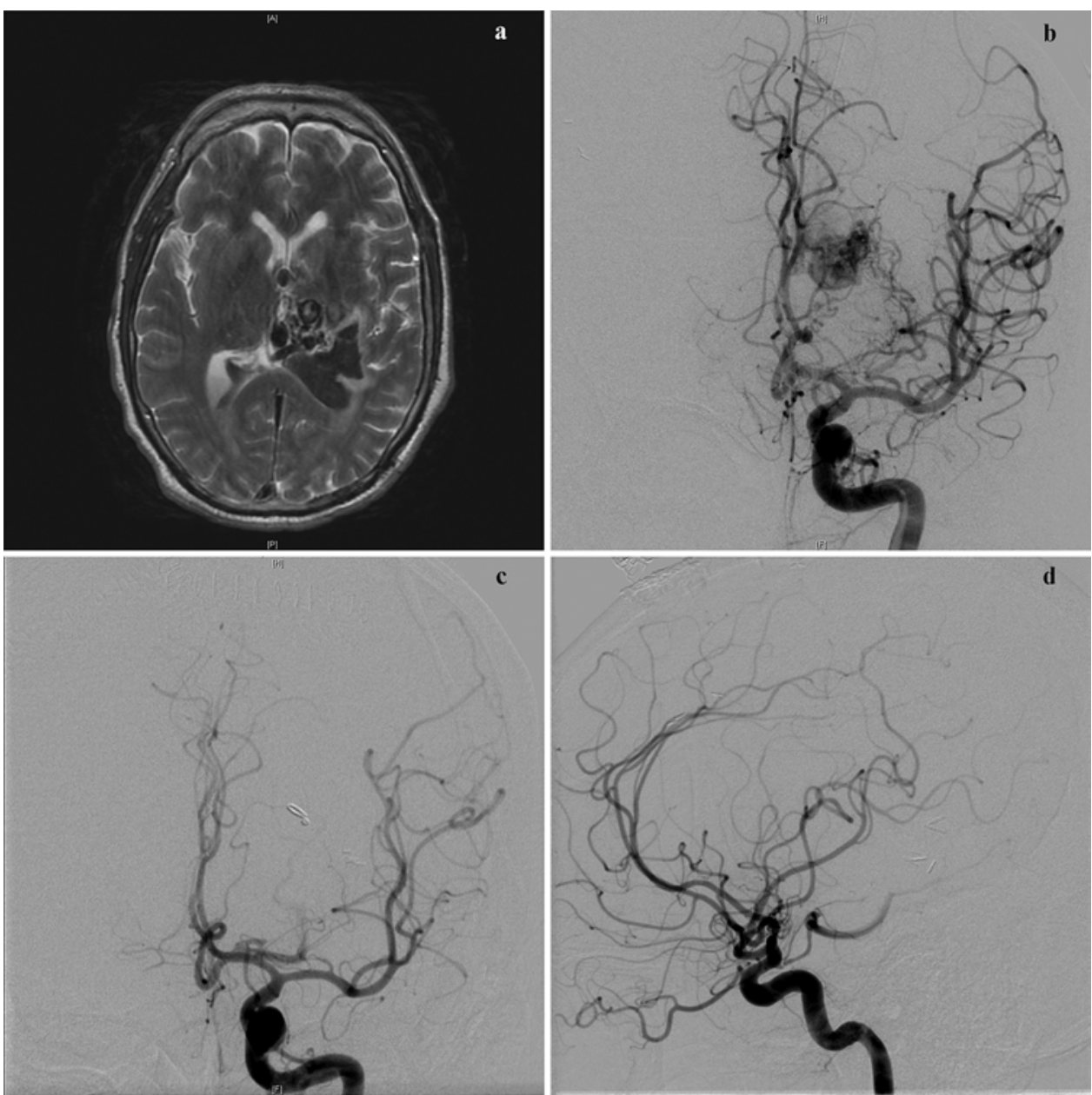

FIG. 1. Thalamic AVM, Spetzler-Martin grade III. The lesion was cured with multimodal management. This patient initially presented with a massive intraventricular hemorrhage. Endovascular embolization of some feeders arising from the left posterior cerebral artery was the first stage in the treatment. Planned partial resection of the nidus was performed in the next stage. Radiation using the CyberKnife system was delivered to the residual lesion, leading to complete cure. a: Axial T2-weighted image showing an AVM in the left thalamus with hemorrhage extending into the lateral ventricles. b: Anteroposterior view of an angiogram showing the nidus, supplied predominantly by the left posterior cerebral artery and draining into the vein of Galen. c: Posttreatment angiogram, anteroposterior view. d: Posttreatment angiogram, lateral view. The posttreatment angiograms show no residual nidus or early draining veins. From chapter 17: Madhugiri VS, Teo M, Steinberg GK: Surgery of basal ganglia, thalamic, and brainstem arteriovenous malformations, in Brain Arteriovenous Malformations and Arteriovenous Fistulas, Dumont AS, Lanzino G, Sheehan JP (eds), 2017, www.thieme.com, Thieme Medical Publishers, Inc. (reprinted with permission).

TABLE 3. Rates of angiographic nidus obliteration stratified by treatment type

\begin{tabular}{|c|c|c|c|c|c|c|c|}
\hline \multirow[b]{2}{*}{$\begin{array}{c}\text { Treatment } \\
\text { Modality/ } \\
\text { Combination }\end{array}$} & \multicolumn{2}{|c|}{ Overall $(n=106)$} & \multirow[b]{2}{*}{$\begin{array}{c}\text { Missing } \\
\text { Angiographic } \\
\text { Data }\end{array}$} & \multicolumn{2}{|c|}{ Lower Grade $(n=54)$} & \multicolumn{2}{|c|}{ High Grade $(n=52)$} \\
\hline & $\begin{array}{c}\text { Radiographic } \\
\text { Cure }(\%)\end{array}$ & $\begin{array}{c}\text { Persistent Nidus } \\
\text { or Early Draining } \\
\text { Vein (\%) }\end{array}$ & & $\begin{array}{c}\text { Radiographic } \\
\text { Cure (\%) }\end{array}$ & $\begin{array}{c}\text { Persistent Nidus } \\
\text { or Early Draining } \\
\text { Vein (\%) }\end{array}$ & $\begin{array}{c}\text { Radiographic } \\
\text { Cure (\%) }\end{array}$ & $\begin{array}{c}\text { Persistent Nidus } \\
\text { or Early Draining } \\
\text { Vein (\%) }\end{array}$ \\
\hline SRS only & $15(41)$ & $22(59)$ & 7 & $15(58)$ & $11(42)$ & & $9(100)$ \\
\hline EVT only & $2(100)$ & & & $2(100)$ & & & \\
\hline Surgery only & $4(80)$ & $1(20)$ & & $4(80)$ & $1(20)$ & & \\
\hline SRS + EVT & $10(31)$ & $22(69)$ & 8 & $7(54)$ & $6(46)$ & $3(16)$ & $16(84)$ \\
\hline SRS + surgery & $5(71)$ & $2(29)$ & & $3(60)$ & $2(40)$ & $2(100)$ & \\
\hline EVT + surgery & $6(100)$ & & & $3(100)$ & & $3(100)$ & \\
\hline All 3 used & $12(71)$ & $5(29)$ & 1 & & & $12(71)$ & $5(29)$ \\
\hline Total & $54(51)$ & $52(49)$ & 16 & $34(63)$ & $20(37)$ & $20(39)$ & $32(61)$ \\
\hline
\end{tabular}

This table presents that subset of patients for whom angiographic follow-up was available. 

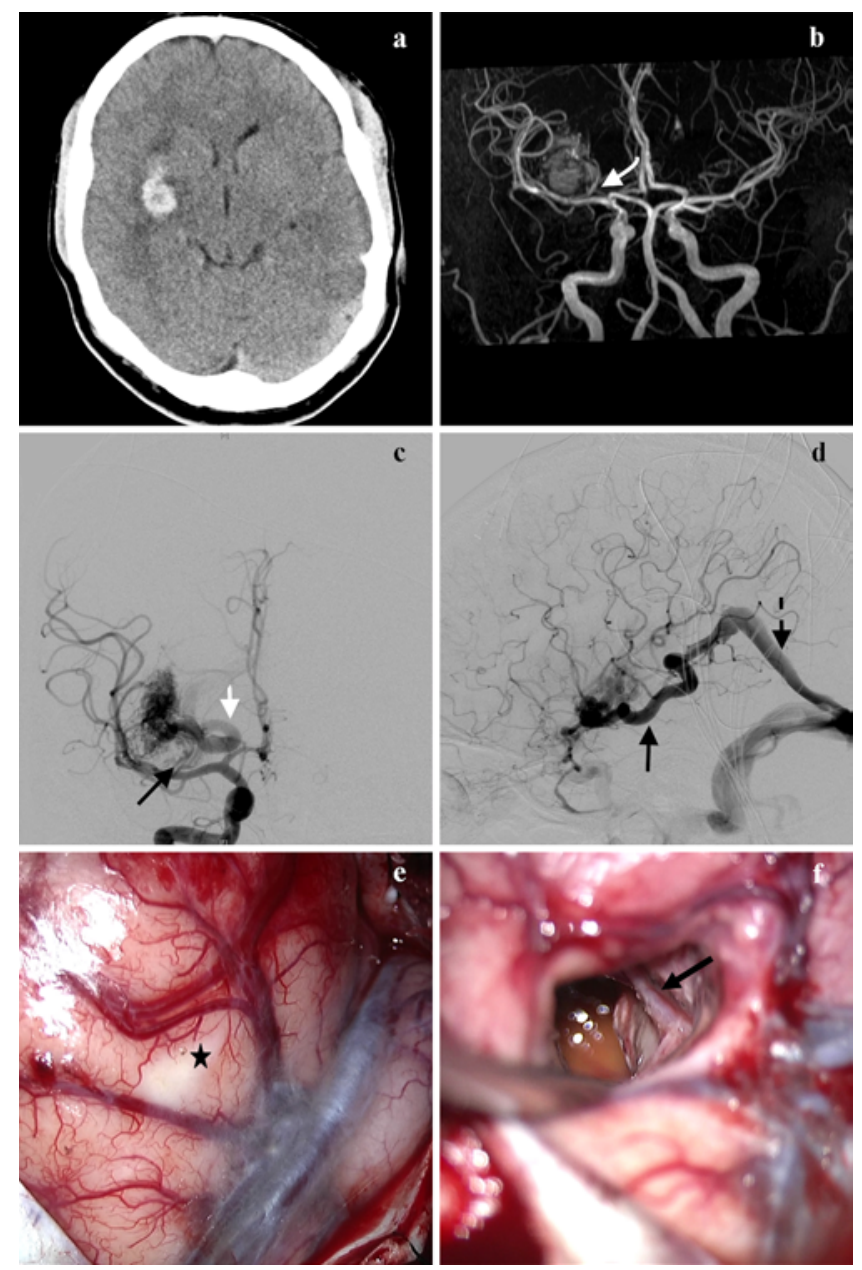

FIG. 2. Capsulo-ganglionic AVM, Spetzler-Martin grade III. The patient presented with sudden loss of consciousness. a: Axial CT image obtained at presentation, showing hemorrhage in the right basal ganglia. b: MR angiogram showing an AVM located just superior to the right $\mathrm{M}_{1}$ segment of the middle cerebral artery. The white arrow points to an enlarged lenticulostriate feeder. c: Anteroposterior projection of a digitally subtracted angiogram showing a nidus measuring $2 \times 1.5 \mathrm{~cm}$, supplied by feeders from the lenticulostriate perforators (black arrow). An early draining vein is seen on the medial aspect of the nidus (white arrow). d: Lateral view of the AVM. The venous drainage into the basal vein of Rosenthal (arrow) and then to the straight sinus (broken arrow) is seen. This lesion was cured by surgery, via a conventional pterional craniotomy and transsylvian approach. e and f: Intraoperative images. The site of corticectomy was on the inferior frontal gyrus, just abutting the sylvian fissure (black star, e). The hematoma and feeders to the nidus could be accessed via this approach. The hematoma has been evacuated, and the first of the lenticulostriate feeders is visible in the walls of the hematoma cavity (arrow, f). From chapter 17: Madhugiri VS, Teo M, Steinberg GK: Surgery of basal ganglia, thalamic, and brainstem arteriovenous malformations, in Brain Arteriovenous Malformations and Arteriovenous Fistulas, Dumont AS, Lanzino G, Sheehan JP (eds), 2017, www.thieme. com, Thieme Medical Publishers, Inc. (reprinted with permission).

123 patients $(94 \%)$. The mean follow-up was $9.5 \pm 7.9$ years from the institution of therapy (median 6.3 years), and the mean follow-up from the last treatment session was $5.9 \pm$ 5.4 years (median 4 years). Prior to institution of treatment, 84 patients (72\%) were in good neurological status (mRS scores $0-2)$, whereas $28 \%$ were in poor neurological status $(\mathrm{n}=32)($ Table 2$)$. At last follow-up, $68.1 \%$ of patients were in good neurological status. There was no correlation between pretreatment $\mathrm{mRS}$ score and outcome. At last follow-up, 75\% of patients had either improved by $1 \mathrm{mRS}$ point or remained the same as pretreatment (good clinical outcome) and $25 \%$ had worsened by 1 or more mRS points (poor clinical outcome). The all-cause mortality rate for this cohort was $8 \%(\mathrm{n}=10) ; 1$ patient died 10 years after documented angiographic cure of an unrelated cause, and thus the lesion-related mortality rate was $7 \%$. Three of these patients died of post-EVT complications and the others of post-SRS rebleed.

Younger patients and those in the pediatric age group did worse than older adults; the mean age of patients who were worse at last follow-up was $18.9 \pm 12.5$ years, whereas that of those who improved was $26.7 \pm 14.5$ years $(\mathrm{p}=$ 0.008 ). At last follow-up, $37.5 \%$ of pediatric patients were worse, as opposed to $16.1 \%$ of adults who worsened after therapy $\left(\chi^{2}=6.8, p=0.009\right)$. Location of the lesion influenced outcome; $77.8 \%$ of patients with extensive AVMs involving the BGT were worse, as were $23.6 \%$ of those with basal ganglia AVMs; in contrast, only $17.3 \%$ of patients with thalamic AVMs had worsened $\left(\chi^{2}=15, \mathrm{p}=0.001\right)$. The maximum nidus diameter, AVM volume, and being high grade influenced outcome; venous drainage did not. No treatment modality appeared to influence outcome. However, only $17 \%$ of patients whose lesions were obliterated had a poor clinical outcome as opposed to $36.5 \%$ of those with persistent lesions $\left(\chi^{2}=10.33, p=0.006\right)$. We performed multivariate analysis using the factors already identified as correlating with outcome. Only maximum AVM diameter $\left(\mathrm{R}^{2}=6.4, \mathrm{p}=0.01\right)$ and AVM volume $\left(\mathrm{R}^{2}\right.$ $=9, \mathrm{p}=0.005)$ independently predicted clinical status at follow-up.

\section{Optimal Outcomes}

The best possible or optimal outcome was when a patient had a good clinical outcome (see above) and angiographic demonstration of obliteration of the AVM at last follow-up. The others, who had either a poor clinical outcome or persistent lesion at last follow-up, were classified as having suboptimal outcomes. Thus, our definition of optimal outcome included clinical as well as angiographic follow-up data; this complete data set was available for 105 patients (Table 4). Of these 105 patients, 44 (42\%) had an optimal outcome. On bivariate analysis, the factors that correlated with having an optimal outcome were location (basal ganglia or thalamus vs BGT, $\mathrm{p}=0.028$ ), smaller nidus diameter $(\mathrm{p}=0.0003)$, smaller AVM volume $(\mathrm{p}=$ $0.036)$, lower grade $(p=0.001)$, and not receiving SRS $(p=$ 0.001 ) (Table 4). We parsed the group into Spetzler-Martin grade < IV and Spetzler-Martin grade IV and V lesions and examined the effect of receiving SRS on each group. In the Spetzler-Martin lower-grade group, SRS had no association with achieving optimal outcomes $(p=0.125)$. In the Spetzler-Martin high-grade group, however, not receiving SRS was associated with an optimal outcome (p $=0.002$ ). We performed multivariate analysis using these variables; only maximum nidus diameter $\left(\mathrm{R}^{2}=0.1, \mathrm{p}=\right.$ $0.06)$, nidus volume $\left(\mathrm{R}^{2}=4.5, \mathrm{p}=0.04\right)$, and inclusion of 

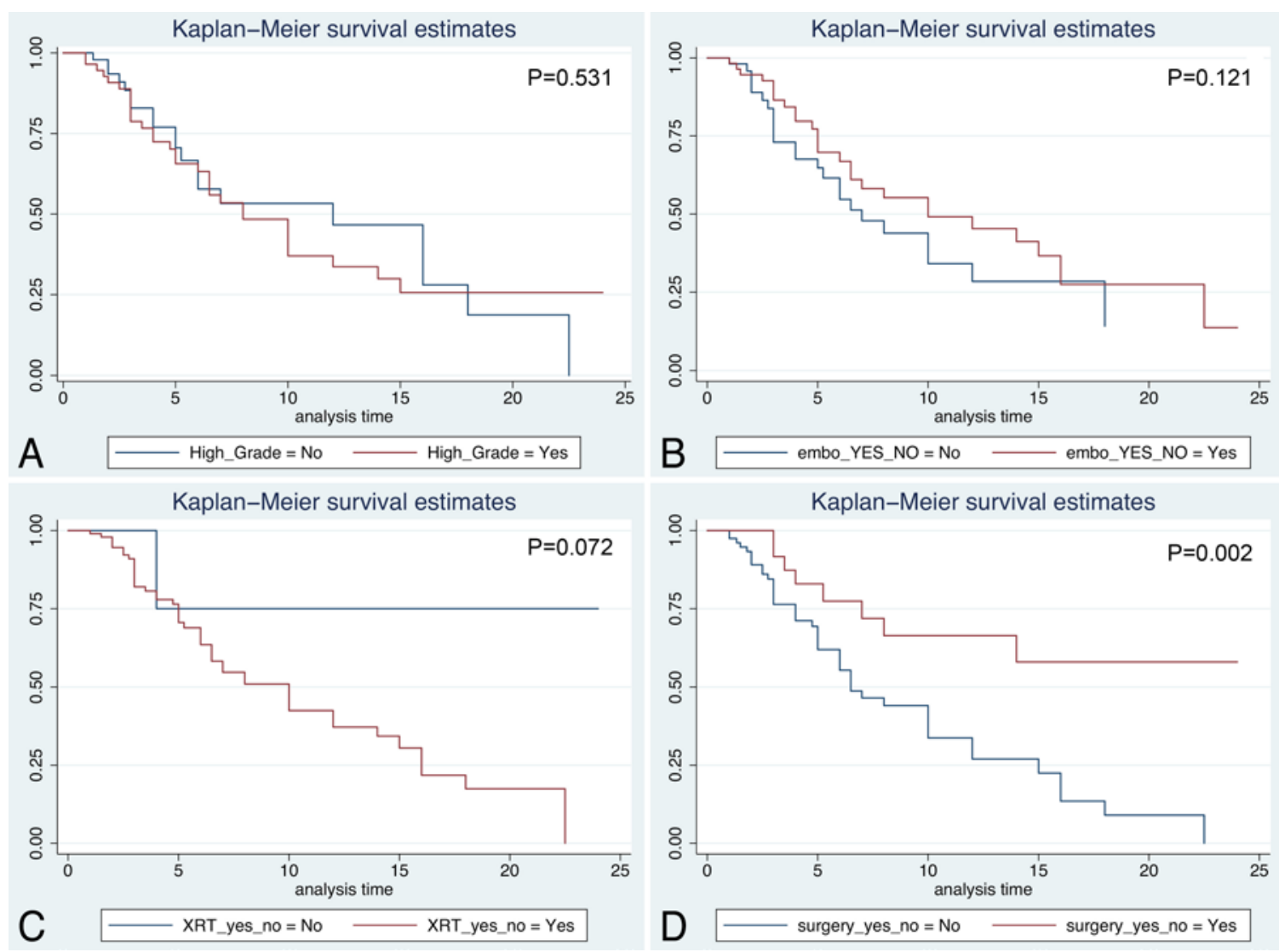

FIG. 3. Kaplan-Meier graphs showing the probability of angiographic obliteration of the nidus over time. The graphs indicate the probability of angiographic obliteration over time, with respect to various dichotomized variables, including high grade $(\mathbf{A})$, received EVT $(B)$, received SRS (C), and underwent surgery (D). The p values listed in the figures are from a Cox proportional hazards regression to check for the significance of the differences between the 2 Kaplan-Meier lines in each plot. embo = embolization; $\mathrm{XRT}=$ radiation therapy.

surgery $\left(\mathrm{R}^{2}=12.2, \mathrm{p}=0.001\right)$ independently predicted optimal outcome.

\section{Discussion}

\section{Natural History of Basal Ganglia and Thalamic AVMs}

BGT AVMs have a greater propensity to bleed than superficial AVMs. ${ }^{3,6,11}$ The majority of deep AVMs present with hemorrhage, and reported incidences of hemorrhagic presentation range from $81 \%{ }^{14}$ to $91 \%$ in various series..$^{23,28}$ In the present series, all but 3 of the patients referred to us were symptomatic for the AVM, and hemorrhage was the initial presenting event in $71 \%$. Sasaki and colleagues reported an annual hemorrhage rate of $11 \%$ in a series of 101 patients, 15 of whom were managed conservatively. ${ }^{28}$ Malik and colleagues reported an annual hemorrhage rate of $49 \% .{ }^{19}$ In the present analysis, the annual PreTP hemorrhage rate was $5.5 \%$ per person-year. All reported hemorrhage rates, however, are derived from hospital databases and may therefore suffer from a significant selection bias. In a previous analysis, we did not report any mortality in patients who experienced rebleeding after diagnosis, but this is probably also an indication of a referral bias; patients with lethal hemorrhages likely did not reach our cen- ter. ${ }^{9}$ Thus, it is probably more appropriate to state that $71 \%$ of all symptomatic patients presented with hemorrhage and in these patients, the annual rate of hemorrhage was $5.5 \%$.

\section{Modalities of Treatment}

BGT AVMs are located in deep and eloquent areas of the brain, and, therefore, SRS has emerged as the treatment modality of choice. Rates of obliteration have ranged between $43 \%$ and $86 \%$ (42\% in this series) across series, and the incidence of post-SRS permanent deficits has ranged between $7 \%$ and $12 \%$ (9.7\% in this series) (Table 5). Discourse about the optimal management of deep/complex AVMs is fraught with controversy. Many authors have advocated SRS as an exclusive or first-line therapy for smaller deep AVMs. ${ }^{1,14,15,22,23,25,26,28}$ However, the obliteration rates after SRS for deep AVMs are lower than those for similarly sized superficial AVMs. ${ }^{22}$ Moreover, SRS does not confer complete immunity from rebleeds during the interval leading up to nidus obliteration (overall PostTP bleed rate of 5.7/person-year in this series). It is, therefore, important that EVT and surgery be included in the management plan as required. We have found that surgery several years after SRS for persistent nidus is made easier due 
TABLE 4. Factors associated with optimal outcomes in 105 of the 122 patients*

\begin{tabular}{|c|c|c|c|}
\hline Factor & $\begin{array}{l}\text { Optimal } \\
\text { Outcome }\end{array}$ & $\begin{array}{l}\text { Suboptimal } \\
\text { Outcome }\end{array}$ & $\begin{array}{c}p \\
\text { Value }\end{array}$ \\
\hline Mean age, yrs & $25.02 \pm 15.6$ & $23.1 \pm 12.9$ & 0.5 \\
\hline No. of children (\%) & $16(35.6)$ & $29(64.4)$ & 0.25 \\
\hline Sex & & & 0.4 \\
\hline Male & $18(37.5)$ & $30(62.5)$ & \\
\hline Female & $26(45.6)$ & $31(54.4)$ & \\
\hline Presented w/ hemorrhage & & & 0.09 \\
\hline Yes & $36(46.7)$ & $41(53.2)$ & \\
\hline No & $8(28.6)$ & $20(71.4)$ & \\
\hline Median no. of bleeds & 1 & 1 & 0.14 \\
\hline $\begin{array}{l}\text { Median mRS score at presen- } \\
\text { tation }\end{array}$ & 2 & 2 & 0.2 \\
\hline $\begin{array}{l}\text { Median mRS score prior to } \\
\text { treatment }\end{array}$ & 2 & 2 & 0.2 \\
\hline Location & & & 0.028 \\
\hline Basal ganglia & $23(52.3)$ & $26(42.6)$ & \\
\hline Thalamus & $21(47.7)$ & $26(42.6)$ & \\
\hline BGT & & $9(14.7)$ & \\
\hline Mean nidus diameter $\pm \mathrm{SD}, \mathrm{cm}$ & $2.8 \pm 1.5$ & $3.9 \pm 1.6$ & 0.0003 \\
\hline Mean nidus vol $\pm \mathrm{SD}, \mathrm{cm}^{3}$ & $28.3 \pm 26.6$ & $66.8 \pm 55.6$ & 0.0365 \\
\hline Venous drainage & & & 0.36 \\
\hline Superficial & $4(66.7)$ & $2(33.3)$ & \\
\hline Deep & $38(41.3)$ & $54(58.7)$ & \\
\hline Mixed & $2(28.6)$ & $5(71.4)$ & \\
\hline SMG & & & 0.001 \\
\hline$<\mathrm{IV}$ & $31(58.5)$ & $22(41.5)$ & \\
\hline IV or V & $13(25)$ & $39(75)$ & \\
\hline EVT & & & 0.85 \\
\hline Yes & 23 (41.1) & $33(58.9)$ & \\
\hline No & $21(42.9)$ & 28 (57.1) & \\
\hline SRS & & & 0.001 \\
\hline Yes & $33(35.9)$ & 59 (64.1) & \\
\hline No & $11(84.6)$ & $2(15.4)$ & \\
\hline Surgery & & & 0.069 \\
\hline Yes & $19(54.3)$ & $16(45.7)$ & \\
\hline No & $25(35.7)$ & $45(64.30)$ & \\
\hline
\end{tabular}

Values are presented as the number of patients (\%) unless stated otherwise. All percentages add up across rows. Mean values are presented as the mean \pm SD. Boldface type indicates statistical significance.

* Optimal outcome is defined as nidus obliterated and clinical status either the same as before treatment or improved.

to the effects of the radiation on the vessels. ${ }^{4,5}$ Blood loss was significantly reduced, and the vessels were partially thrombosed or thickened due to endothelial proliferation, making handling and coagulation of vessels easier. Thus, it would be reasonable to consider surgery after SRS if the nidus were to persist after repeated sessions and a reasonable period of time.

Embolization is a very useful adjunct in the management of deep AVMs, in combination with either surgery or SRS. It is, however, rarely curative for BGT AVMs when used in isolation. In the series reported by Paulsen and colleagues $(n=38)$, a cure was seen in only 1 patient with EVT alone. ${ }^{24}$ In the present series, only 2 patients had EVT as the sole treatment, and EVT was able to cure the lesion in these patients. We recommend staged EVT with planned obliteration of $<50 \%$ of the nidus in each sitting. The use of intraprocedural neuromonitoring and provocative testing is essential to reduce the incidence of complications. While some studies have suggested that pre-SRS embolization decreases the rate of AVM obliteration after SRS, our Stanford University group has shown that it can safely and effectively reduce the treatment volume before SRS, without adversely affecting rates of AVM obliteration or of excellent clinical outcome. ${ }^{20}$

Surgery was performed for select deep BGT AVMs that presented to either a pial or ependymal surface. Occasionally, the presence of a hematoma or a gliotic cavity affords access to the AVM, making resection feasible. In the series of 11 patients described by Liu and Lee, all of whom had compete excision of their lesions, 11 patients (69\%) either improved or remained neurologically stable. ${ }^{17}$ In a mixed series of deep AVMs, Lawton and colleagues reported complete excision in $43 \%$ of 22 patients. ${ }^{16}$ The incidence of treatment-related permanent deficits was $9 \%$. Sasaki and colleagues reported a series of 101 patients with BGT AVMs, of whom 15 patients had microsurgery.28 All AVMs were excised completely, and 10 patients had returned to work at last follow-up. In the present series, 36 patients $(29 \%)$ had surgery as part of their treatment protocol. Thirteen patients had Spetzler-Martin grade III lesions, and 22 had high-grade lesions. Only 5 patients had surgery alone as therapy - of these, 1 patient had a grade II lesion and 4 patients had grade III AVMs. All lesions were completely excised, and the incidence of permanent postsurgical deficits was $7.5 \%$. We believe that surgery has an important role to play in the management of BGT AVMs. While in a select group of patients surgery alone can cure the AVM, in most others, it achieves volume reduction for future SRS or is employed years post-SRS.

\section{Predictors of Radiographic Cure and Clinical Outcome}

Obliteration of the AVM is the first requisite to protect against further hemorrhage and worsening of neurological status. Kano et al. reported a series of 133 BGT AVMs for which lesion location in the basal ganglia, a smaller target volume, a smaller maximum diameter, and a higher margin dose were associated with higher rates of obliteration. ${ }^{13}$ In this series, inclusion of SRS and surgery in the treatment plan were the only factors that independently predicted obliteration. The effect of surgery on the obliteration rate was more marked for high-grade lesions, and on multivariate analysis it remained an independent predictor of outcome. This emphasizes our strategy of resecting residual AVMs if multiple sessions of EVT and/or SRS fail to obliterate the lesion after 3-5 years. Alongside obliteration, good clinical outcome is the second goal of treatment. In the present series, only lesion factors correlated with clinical outcomes; younger age, location in the basal ganglia and thalamus, greater nidus diameter and volume, and angiographic persistence of the lesion were associated 
TABLE 5. Summary of current radiosurgery literature

\begin{tabular}{|c|c|c|c|c|c|c|}
\hline Authors \& Year & Patients & Radiotherapy & Volume/Size & Dose (Gy) & Outcome & Obliteration \\
\hline Sasaki et al., 1998 & $\begin{array}{c}66 \text { (56 grade II or III, } \\
10 \text { grade IV or V) }\end{array}$ & GKS & NA & NA & $7 \%$ PD & $86 \%$ \\
\hline $\begin{array}{l}\text { Pollock \& Flickinger, 2002; } \\
\text { Pollock et al., } 2004\end{array}$ & 56 (40 BG/thalamic) & GKS & Median $3.8 \mathrm{~cm}^{3}$ & 18 & $12 \% \mathrm{PD}$ & $43 \%$ \\
\hline Nicolato et al., 2002 & 33 & GKS & Mean $2.96 \mathrm{~cm}^{3}$ & 21.6 & $8 \%(4 \% \mathrm{PD})$ & $81 \%$ \\
\hline $\begin{array}{l}\text { Andrade-Souza et al., } \\
2005\end{array}$ & 42 & LINAC & Mean 4.7, median 2.8 & 16,15 & $19 \%(12 \%$ PD) & $62 \%$ \\
\hline Kiran et al., 2009 & 53 (47 BG/thalamic) & GKS & Mean 4.3, median 1.9 & 23.3 & $15 \%(7.5 \%$ PD) & $74 \%$ \\
\hline Nagy et al., 2012 & 161 thalamic, 56 BG & GKS & Median $2 \mathrm{~cm}^{3}$ & $17.5-25$ & $\begin{array}{l}50 \% \text { good outcomes } \\
\text { even for }>8 \mathrm{~cm}^{3}\end{array}$ & $\begin{array}{l}88 \% \text { for }<0.5 \mathrm{~cm}^{3}, 47 \% \\
\quad \text { for }>8 \mathrm{~cm}^{3}\end{array}$ \\
\hline Kano et al., 2012 & 77 thalamic, 56 BG & GKS & $\begin{array}{l}\text { Median } 2.7 \mathrm{~cm}^{3}, 2-\mathrm{cm} \\
\quad \text { diameter }\end{array}$ & 38 & $\begin{array}{l}4.5 \% \text { adverse ef- } \\
\text { fects }\end{array}$ & $72 \%$ at $10 \mathrm{yrs}$ \\
\hline Present series & $\begin{array}{r}109 \text { (52 SMG II-III, } \\
57 \text { SMG IV or V) }\end{array}$ & Various & Mean $3.6 \mathrm{~cm}$ & 20.9 & $\begin{array}{l}75 \% \text { good outcome } \\
\quad(9.7 \% \text { PD) }\end{array}$ & $\begin{array}{l}42 \%(34.7 \% \text { if SMG IV \& } \\
\quad \text { V, } 56.8 \% \text { for SMG <IV) }\end{array}$ \\
\hline
\end{tabular}

$\mathrm{BG}=$ basal ganglia; $\mathrm{NA}=$ not applicable; $\mathrm{PD}=$ permanent deficit.

with poor clinical outcome. However, only nidus size and volume independently predicted the clinical outcome in multivariate analyses.

The optimal outcome is a composite of clinical and radiological outcomes. It is interesting to note that smaller nidus size (and volume), as well as not receiving SRS, correlated well with the optimal outcome in bivariate analyses. This could be because higher rates of complications such as radiation necrosis or hemorrhage are likely after SRS for larger, high-grade lesions. ${ }^{13}$ These complications could lead to lower rates of optimal outcomes. However, this association was not borne out on multivariate analysis, where maximum nidus diameter, nidus volume, and inclusion of surgery were the only factors that predicted optimal outcome. This underscores the necessity for multimodal management of BGT AVMs, especially for larger lesions, where the outcome is likely to be poor.

This study clearly establishes that treatment modalities (surgery and SRS) affect obliteration rates and lesion characteristics (diameter and volume) affect clinical outcomes. However, in a novel analysis, when we studied the group of patients with good clinical outcomes and lesion obliteration, lesion size and inclusion of surgery both predicted optimal outcomes.

\section{Conclusions}

Basal ganglionic and thalamic AVMs are difficult lesions to treat, and no single modality of treatment is generally successful in obliterating these lesions when employed in isolation. Thus, a multipronged approach including SRS, EVT, and surgery is generally required. The factors that predicted clinical outcome were nidus size and volume, and the factors that predicted angiographic obliteration were inclusion of SRS and surgery (especially for large lesions) in the treatment plan. Overall, the nidus size and inclusion of surgery in the treatment plan predicted optimal outcomes. Treatment of patients harboring these complex lesions is almost always multimodal and needs to be highly individualized depending on the clinical presen- tation, lesion characteristics, the patient's neurological and general physical condition, and expertise available.

\section{Acknowledgments}

This study was supported in part by Russell and Elizabeth Siegelman, Bernard and Ronni Lacroute, and the William Randolph Hearst Foundation (G.K.S.).

We thank Cindy H. Samos and Christine Plant for editorial assistance.

\section{References}

1. Andrade-Souza YM, Zadeh G, Scora D, Tsao MN, Schwartz ML: Radiosurgery for basal ganglia, internal capsule, and thalamus arteriovenous malformation: clinical outcome. Neurosurgery 56:56-64, 2005

2. Bonita R, Beaglehole R: Recovery of motor function after stroke. Stroke 19:1497-1500, 1988

3. Brown RD Jr, Wiebers DO, Forbes G, O'Fallon WM, Piepgras DG, Marsh WR, et al: The natural history of unruptured intracranial arteriovenous malformations. J Neurosurg 68:352-357, 1988

4. Chang SD, Marcellus ML, Marks MP, Levy RP, Do HM, Steinberg GK: Multimodality treatment of giant intracranial arteriovenous malformations. Neurosurgery 53:1-13, 2003

5. Chang SD, Steinberg, Levy RP, Marks MP, Frankel KA, Shuster DL, et al: Microsurgical resection of incompletely obliterated intracranial arteriovenous malformations following stereotactic radiosurgery. Neurol Med Chir (Tokyo) 38 Suppl:200-207, 1998

6. Crawford PM, West CR, Chadwick DW, Shaw MD: Arteriovenous malformations of the brain: natural history in unoperated patients. J Neurol Neurosurg Psychiatry 49:1-10, 1986

7. Davidson AS, Morgan MK: How safe is arteriovenous malformation surgery? A prospective, observational study of surgery as first-line treatment for brain arteriovenous malformations. Neurosurgery 66:498-505, 2010

8. de Oliveira E, Tedeschi H, Siqueira MG, Ono M, Rhoton AL Jr: Arteriovenous malformations of the basal ganglia region: rationale for surgical management. Acta Neurochir (Wien) 139:487-506, 1997

9. Fleetwood IG, Marcellus ML, Levy RP, Marks MP, Steinberg GK: Deep arteriovenous malformations of the basal ganglia 
and thalamus: natural history. J Neurosurg 98:747-750, 2003

10. Friedman WA, Bova FJ, Mendenhall WM: Linear accelerator radiosurgery for arteriovenous malformations: the relationship of size to outcome. J Neurosurg 82:180-189, 1995

11. Graf CJ, Perret GE, Torner JC: Bleeding from cerebral arteriovenous malformations as part of their natural history. $\mathbf{J}$ Neurosurg 58:331-337, 1983

12. Heros RC, Korosue K, Diebold PM: Surgical excision of cerebral arteriovenous malformations: late results. Neurosurgery 26:570-578, 1990

13. Kano H, Kondziolka D, Flickinger JC, Yang HC, Flannery TJ, Niranjan A, et al: Stereotactic radiosurgery for arteriovenous malformations, Part 4: management of basal ganglia and thalamus arteriovenous malformations. J Neurosurg 116:33-43, 2012

14. Kiran NA, Kale SS, Kasliwal MK, Vaishya S, Gupta A, Singh Sharma M, et al: Gamma knife radiosurgery for arteriovenous malformations of basal ganglia, thalamus and brainstem-a retrospective study comparing the results with that for AVMs at other intracranial locations. Acta Neurochir (Wien) 151:1575-1582, 2009

15. Kobayashi T, Tanaka T, Kida Y, Oyama H, Niwa M, Maesawa S: [Gamma knife treatment of AVM of the basal ganglia and thalamus.] No To Shinkei 48:351-356, 1996 (Jpn)

16. Lawton MT, Hamilton MG, Spetzler RF: Multimodality treatment of deep arteriovenous malformations: thalamus, basal ganglia, and brain stem. Neurosurgery 37:29-36, 1995

17. Liu KD, Lee LS: Microsurgical treatment of deep arteriovenous malformations--basal ganglia and thalamus. Zhonghua Yi Xue Za Zhi (Taipei) 64:23-30, 2001

18. Lunsford LD, Kondziolka D, Flickinger JC, Bissonette DJ, Jungreis CA, Maitz AH, et al: Stereotactic radiosurgery for arteriovenous malformations of the brain. $\mathbf{J}$ Neurosurg 75:512-524, 1991

19. Malik GM, Umansky F, Patel S, Ausman JI: Microsurgical removal of arteriovenous malformations of the basal ganglia. Neurosurgery 23:209-217, 1988

20. Marks MP, Marcellus ML, Santarelli J, Dodd RL, Do HM, Chang SD, et al: Embolization followed by radiosurgery for the treatment of brain arteriovenous malformations (AVMs). World Neurosurg 99:471-476, 2017

21. Mizoi K, Yoshimoto T, Nagamine Y, Takahashi A, Ezura M: Surgical removal of giant basal ganglia arteriovenous malformations through the extended transsylvian approach following preoperative embolization--two case reports. Neurol Med Chir (Tokyo) 35:869-875, 1995

22. Nagy G, Major O, Rowe JG, Radatz MW, Hodgson TJ, Coley SC, et al: Stereotactic radiosurgery for arteriovenous malformations located in deep critical regions. Neurosurgery 70:1458-1471, 2012

23. Nicolato A, Foroni R, Crocco A, Zampieri PG, Alessandrini $\mathrm{F}$, Bricolo A, et al: Gamma knife radiosurgery in the management of arteriovenous malformations of the basal ganglia region of the brain. Minim Invasive Neurosurg 45:211-223, 2002

24. Paulsen RD, Steinberg GK, Norbash AM, Marcellus ML,
Marks MP: Embolization of basal ganglia and thalamic arteriovenous malformations. Neurosurgery 44:991-997, 1999

25. Pollock BE, Flickinger JC: A proposed radiosurgery-based grading system for arteriovenous malformations. J Neurosurg 96:79-85, 2002

26. Pollock BE, Gorman DA, Brown PD: Radiosurgery for arteriovenous malformations of the basal ganglia, thalamus, and brainstem. J Neurosurg 100:210-214, 2004

27. Rankin J: Cerebral vascular accidents in patients over the age of 60. II. Prognosis. Scott Med J 2:200-215, 1957

28. Sasaki T, Kurita H, Saito I, Kawamoto S, Nemoto S, Terahara A, et al: Arteriovenous malformations in the basal ganglia and thalamus: management and results in 101 cases. J Neurosurg 88:285-292, 1998

29. Sheps MC: On the person years concept in epidemiology and demography. Milbank Mem Fund Q 44:69-91, 1966

30. Steinberg GK, Fabrikant JI, Marks MP, Levy RP, Frankel KA, Phillips MH, et al: Stereotactic heavy-charged-particle Bragg-peak radiation for intracranial arteriovenous malformations. N Engl J Med 323:96-101, 1990

31. U HS, Kerber CW, Todd MM: Multimodality treatment of deep periventricular cerebral arteriovenous malformations. Surg Neurol 38:192-203, 1992

32. Yamada K, Mase M, Matsumoto T: Surgery for deeply seated arteriovenous malformation: with special reference to thalamic and striatal arteriovenous malformation. Neurol Med Chir (Tokyo) 38 Suppl:227-230, 1998

33. Yamagata S, Kikuchi H, Ihara I, Nagata I, Naruo Y, Shishido $\mathrm{H}$, et al: [Intraoperative liquid embolization of an arteriovenous malformation in the basal ganglia and thalamic region.] No Shinkei Geka 15:717-723, 1987 (Jpn)

\section{Disclosures}

Dr. Steinberg is a consultant for Qool Therapeutics, Peter Lazic US, Inc., and NeuroSave.

\section{Author Contributions}

Conception and design: Steinberg, Madhugiri. Acquisition of data: Madhugiri, Teo, Westbroek, Chang, Marks, Do, Levy. Analysis and interpretation of data: Steinberg, Madhugiri, Teo, Westbroek, Marks, Levy. Drafting the article: Madhugiri, Teo. Critically revising the article: Steinberg, Teo, Chang, Marks. Reviewed submitted version of manuscript: Steinberg, Madhugiri, Teo, Do. Approved the final version of the manuscript on behalf of all authors: Steinberg. Statistical analysis: Madhugiri, Teo. Administrative/technical/material support: Steinberg. Study supervision: Steinberg. Patient recruitment: Steinberg. Patient recruitment and management: Marks, Levy.

\section{Correspondence}

Gary K. Steinberg: Stanford University School of Medicine, Stanford,CA. gsteinberg@stanford.edu. 